\title{
The Effect of Antioxidant Treatment and NOS Inhibition on the Incidence of Ischemia-Induced Arrhythmias in the Diabetic Rat Heart
}

\author{
J. MATEJÍKOVÁ, J. KUCHARSKÁ ${ }^{1}$, D. PANCZA, T. RAVINGEROVÁ
}

Institute for Heart Research, Slovak Academy of Sciences, Centre of Excellence for Cardiovascular Research of the SAS, ${ }^{1}$ Pharmacobiochemical Laboratory, Faculty of Medicine, Comenius University, Bratislava, Slovakia

Received January 25, 2008

Accepted March 25, 2008

On-line March 28, 2008

\begin{abstract}
Summary
Contrary to clinical trials, experimental studies revealed that diabetes mellitus (DM) may initiate, besides increased myocardial vulnerability to ischemia-reperfusion injury (I/R) and pro/antioxidant dysbalance, development of adaptation leading to an enhanced tolerance to $I / R$. The aims were to characterize 1) susceptibility to ischemia-induced ventricular arrhythmias in the diabetic rat heart 2) its response to antioxidant $\mathrm{N}$-acetylcysteine (NAC) and a NOS inhibitor L-NAME, and 3) the effect of DM on endogenous antioxidant systems. Seven days after streptozotocin injection (65 mg/kg, i.p.), Langendorffperfused control (C) and DM hearts were subjected to 30-min occlusion of the LAD coronary artery with or without prior $15-\mathrm{min}$ treatment with L-NAME $(100 \mu \mathrm{M})$ or NAC $(4 \mathrm{mM})$. Total number of ventricular premature beats (VPB), as well the total duration of ventricular tachycardia (VT) were reduced in the DM group (from $533 \pm 58$ and $37.9 \pm 10.2 \mathrm{~s}$ to $224.3 \pm 52.6$ and $19 \pm 13.5 \mathrm{~s}$; $\mathrm{P}<0.05)$. In contrast to the antiarrhythmic effects of L-NAME and NAC in controls group (VPB $290 \pm 56$ and $74 \pm 36$, respectively; $\mathrm{P}<0.01$ vs. control hearts), application of both drugs in the diabetics did not modify arrhythmogenesis (L-NAME: VPB $345 \pm 136$, VT $25 \pm 13 \mathrm{~s}$; NAC: VPB $207 \pm 50$, VT $12 \pm 3.9 \mathrm{~s}$; P>0.05 vs non-treated diabetic hearts). Diabetic state was associated with significantly elevated levels of $\mathrm{CoQ}_{10}$ and $\mathrm{CoQ}_{9}(19.6 \pm 0.8$ and $217.3 \pm 9.5$ vs. $17.4 \pm 0.5$ and $185.0 \pm 5.0 \mathrm{nmol} / \mathrm{g}$, respectively, in controls; $\mathrm{P}<0.05)$, as well as $\alpha$-tocopherol $(38.6 \pm 0.7$ vs. $31.5 \pm 2.1 \mathrm{nmol} / \mathrm{g}$ in controls; $\mathrm{P}<0.01)$ in the myocardial tissue. It is concluded that early period of DM is associated with enhanced resistance to ischemia-induced arrhythmias. Diabetes mellitus might induce adaptive processes in the myocardium leading to lower susceptibility to antioxidant and L-NAME treatment.
\end{abstract}

\section{Key words}

Myocardial ischemia - Arrhythmias - Antioxidant treatment • Adaptation

\section{Corresponding author}

T. Ravingerová, Institute for Heart Research, Slovak Academy of Sciences, POB 104, Dúbravská cesta 9, 84005 Bratislava, Slovak Republic. Fax: 421254776637. E-mail: usrdravi@savba.sk

\section{Introduction}

Although epidemiological and clinical data have clearly demonstrated that diabetic patients are more prone to ischemic heart disease (Kannel and McGee 1979, Malberg and Ryden 1988), experimental studies have revealed controversies in the sensitivity of the diabetic heart to ischemia/reperfusion injury. Increased (Paulson 1997), decreased (Kusama et al. 1992, Liu et al. 1993) and unchanged (Tosaki et al. 1996) susceptibility to myocardial ischemia/reperfusion injury have been reported in different animal models. Conflicting data may be partially explained by different duration and severity of the diabetic state, the differences between the species (e.g. dogs with diabetes are supposed to be more sensitive to ischemia and develop larger infarcts than normal dogs (Forrat et al. 1993), whereas in the diabetic rabbits and rats infarct size is smaller than in the non-diabetic animals (Liu et al. 1993, Hadour et al. 1998) experimental models and protocols, severity and type of ischemia, as well as by the choice of the end-points studies, since protection against myocardial stunning does not seem to involve similar mechanisms as limitation of infarction and abolition of arrhythmias (Feuvray and Lopaschuk 1997).

Several mechanisms have been proposed to explain a lower sensitivity to ischemia/reperfusion in the diabetic heart. The alterations in the intracellular $\mathrm{pH}$, a 
decreased clearance of protons via $\mathrm{Na}^{+} / \mathrm{H}^{+}$exchanger, a decreased rate of glycolysis in the diabetic myocardium may represent the main possible mechanisms of this attenuated response to ischemia/reperfusion injury (Pierce et al. 1990, Galinanes and Fowler 2004).

It is generally accepted that reactive oxygen species (ROS) take part in the development of chronic diabetic complications. However, little information is available about regulation of the endogenous level of antioxidants in the state of pro/antioxidant dysbalance in relation to the development of diabetes (Singal et al. 2001).

Nitric oxide (NO) plays multiple roles in the cardiovascular system mediating a number of physiological and pathophysiological processes. It has been hypothesized that the toxicity of NO is more likely resulting from its reaction with superoxide anion to produce a potent oxidant peroxynitrite that can exert cytotoxicity via its reaction with numerous molecular targets and appears to be potentially injurious to myocardial tissue (Lecour et al. 2001, Ferdinandy and Schulz 2003). On the other hand, a lot of studies demonstrated that NO as a signaling molecule plays a fundamental biological role in protecting the heart against ischemia/reperfusion injury (Bolli 2001). In addition, the role of NO in antiarrhythmic protection conferred by ischemic preconditioning has been also characterized (Vegh et al. 1992). However, the controversial role of $\mathrm{NO}$ in the ischemia/reperfusion injury of the myocardium (Andelová et al. 2005) has been less studied in a setting of the diabetic heart.

The aim of our study was to characterize susceptibility to ischemia-induced ventricular arrhythmias in the diabetic rat heart and its response to antioxidant $\mathrm{N}$-acetylcysteine (NAC) and a NO synthase (NOS) inhibitor $\mathrm{N}^{\omega}$-nitro-L-arginine methyl ester (L-NAME). Our further goal was to characterize the effect of DM on endogenous antioxidant systems.

\section{Methods}

\section{Animals}

Male Wistar rats (250-300 $\mathrm{g}$ body weight), fed a standard diet and tap water ad libitum, were employed. All studies were performed in accordance with the Guide for the Care and Use of Laboratory Animals published by US National Institutes of Health (NIH publication No 85-23, revised 1996) and approved by the Animal Care and Use Committee of the Slovak Republic.

\section{Induction of diabetes mellitus (DM)}

Diabetes was induced by a single i.p. injection of streptozotocin $(65 \mathrm{mg} / \mathrm{kg})$ dissolved in $0.1 \mathrm{M}$ citrate buffer, whereas control animals received an equal amount of the vehicle. Following 1 week, the diabetic animals, as well as the age-matched controls ones were subjected to the following protocol.

\section{Perfusion technique}

Rats were anesthetized (sodium pentobarbitone, $60 \mathrm{mg} / \mathrm{kg}$, i.p.) and given heparin (500 IU, i.p.). Hearts were rapidly excised, placed in ice-cold perfusion buffer, cannulated via the aorta and perfused in the Langendorff mode at a constant perfusion pressure of $70 \mathrm{~mm} \mathrm{Hg}$ and at $37{ }^{\circ} \mathrm{C}$. The perfusion solution was a modified KrebsHenseleit buffer gassed with $95 \% \mathrm{O}_{2}$ and $5 \% \mathrm{CO}_{2}(\mathrm{pH}$ 7,4) containing (in $\mathrm{mM}$ ): $\mathrm{NaCl} 118.0 ; \mathrm{KCl} 3.0 ; \mathrm{MgSO}_{4}$ 1.2; $\mathrm{NaHCO}_{3}$ 25.0; $\mathrm{NaH}_{2} \mathrm{PO}_{4}$ 1.18; $\mathrm{CaCl}_{2}$ 2.5; glucose 11.1. Reduced potassium and enhanced calcium concentrations in the above buffer were used to promote arrhythmogenesis during ischemia.

Solution was filtered through a $5 \mu \mathrm{m}$ porosity filter (Millipore) to remove contaminants. An epicardial electrogram was registered by means of two stainless steel electrodes attached to the apex of the heart and the aortic cannula.

Left ventricular pressure was measured by means of a non-elastic water-filled balloon inserted into the left ventricle via the left atrium (adjusted to obtain end-diastolic pressure of 5-7 $\mathrm{mm} \mathrm{Hg}$ ) and connected to a pressure transducer (MLP844 Physiological Pressure Transducer, ADInstruments). Left ventricular developed pressure (LVDP, systolic minus diastolic pressure), maximal rates of pressure development and fall, $+\mathrm{dP} / \mathrm{dt}_{\max }$ and $-\mathrm{dP} / \mathrm{dt}_{\max }$, as the indexes of contraction and relaxation, as well as the heart rate (derived from electrogram) and coronary flow were monitored during stabilization, preischemia period (for the evaluation of the effect of pharmacological interventions on hemodynamic parameters), and were continuously recorded until the end of experiment. Heart function and arrhythmias were analyzed using PowerLab/8SP Chart 5 software (ADInstruments). The hearts were allowed to stabilize (20 $\mathrm{min}$ ) before further interventions.

\section{Quantification of arrhythmias}

Susceptibility to ischemia-induced ventricular arrhythmias was analyzed from the electrogram recording following the guidelines for the study of ischemia and 
Table 1. Preischemic values of hemodynamic parameters of isolated rat hearts.

\begin{tabular}{|c|c|c|c|c|c|c|}
\hline Parameters & $\begin{array}{c}C \\
(n=11)\end{array}$ & $\begin{array}{c}\text { Non-diabet } \\
\text { L-NAME } \\
(\mathbf{n}=\mathbf{1 0})\end{array}$ & $\begin{array}{c}\text { NAC } \\
(n=7)\end{array}$ & $\begin{array}{c}C \\
(n=7)\end{array}$ & $\begin{array}{l}\text { Diabetic } \\
\text { L-NAME } \\
(n=7)\end{array}$ & $\begin{array}{c}\text { NAC } \\
(n=6)\end{array}$ \\
\hline $\begin{array}{l}H R \\
\text { (beats/min) }\end{array}$ & $274 \pm 7$ & $262 \pm 4$ & $261 \pm 5$ & $231 \pm 7 *$ & $224 \pm 4^{*}$ & $220 \pm 7 *$ \\
\hline $\begin{array}{l}C F \\
(\mathrm{ml} / \mathrm{min})\end{array}$ & $11.4 \pm 0.4$ & $12.2 \pm 0.5$ & $12 \pm 1$ & $11 \pm 5$ & $12 \pm 0.4$ & $12.4 \pm 2$ \\
\hline $\begin{array}{l}+d P / d t_{\max } \\
(\mathrm{mmHg} / \mathrm{s})\end{array}$ & $3120 \pm 180$ & $2852 \pm 240$ & $2719 \pm 230$ & $2307 \pm 180 *$ & $2403 \pm 120 * *$ & $2320 \pm 150^{*}$ \\
\hline $\begin{array}{l}-d P / d t_{\max } \\
(m m H g / s)\end{array}$ & $1959 \pm 160$ & $1860 \pm 110$ & $1729 \pm 111$ & $1577 \pm 150 *$ & $1678 \pm 140 *$ & $1596 \pm 94 *$ \\
\hline $\begin{array}{l}L V D P \\
(m m H g)\end{array}$ & $94 \pm 3$ & $85 \pm 3$ & $79 \pm 6$ & $75 \pm 20$ & $78 \pm 6$ & $74 \pm 5$ \\
\hline
\end{tabular}

Data are means \pm S.E.M., $n=6-11$ in each group. CF - coronary flow; LVDP - left ventricular developed pressure (LV systolic minus LV diastolic pressure); $+\mathrm{dP} / \mathrm{dt}_{\max }$, and $-\mathrm{dP} / \mathrm{dt}_{\max }-$ maximal rates of pressure development and fall, respectively; $\mathrm{HR}-\mathrm{heart}$ rate. $* \mathrm{P}<0.05$ vs. non-diabetic control hearts.

reperfusion arrhythmias known as the Lambeth Conventions (Walker et al. 1988). We focused on the measurement of the total number of ventricular premature beats (VPB) over the whole period of ischemia, as well as on duration of ventricular tachycardia (VT), which was defined as a run of four or more consecutive ectopic beats.

\section{Experimental protocols}

Hearts of all groups (diabetic and non-diabetic) were subjected to $30-\mathrm{min}$ occlusion of LAD coronary artery without or with prior 15-min treatment with L-NAME $(100 \mu \mathrm{M})$ or NAC $(4 \mathrm{mM})$. In parallel nontreated subgroups, the levels of coenzyme $\mathrm{Q}(\mathrm{CoQ})_{10}$, $\mathrm{CoQ}_{9}$ and alpha-tocopherol ( $\alpha$-toc) in the left ventricular tissue of the non-diabetic and diabetic control hearts were measured by HPLC (Lang et al. 1986).

\section{Statistical evaluation}

The data were expressed as means \pm S.E.M. ANOVA and subsequent post-hoc tests (Mann-Whitney $\mathrm{U}$ test and Student's t test) were used to compare the differences in the number of VPB, total duration of VT and concentration of $\mathrm{CoQ}_{10}$ and $\alpha$-toc between groups. Differences were considered significant when $\mathrm{P}<0.05$.

\section{Results}

Development of the diabetic state was confirmed by significantly $(\mathrm{P}<0.05)$ increased blood glucose levels $(17.4 \pm 0.7 \mathrm{mmol} / \mathrm{l})$ as compared with $5.7 \pm 0.1 \mathrm{mmol} / \mathrm{l}$ in the non-diabetic controls. A delay in the body weight growth was also observed in the diabetic rats $(286 \pm 14 \mathrm{~g})$ as compared with the control animals $(329 \pm 6 \mathrm{~g} ; \mathrm{P}<0.05)$, as well as an increase in a relative heart weight (heart weight to body weight ratio; $3.1 \pm 0.3$ vs. $2.4 \pm 0.1$ in the controls; $\mathrm{P}<0.05)$.

\section{Characteristics of isolated hearts}

Preischemic values of heart rate, LVDP, $+\mathrm{dP} / \mathrm{dt}_{\max }$ and $-\mathrm{dP} / \mathrm{dt}_{\max }$, as well as of coronary flow in the control non-diabetic and diabetic groups, as well as in drug-treated and non-treated hearts are summarized in Table 1. Evaluation of cardiac function revealed a significant reduction in heart rate in all diabetic hearts. Although there were no differences in LVDP between the groups, both $+\mathrm{dP} / \mathrm{dt}_{\max }$ and $-\mathrm{dP} / \mathrm{dt}_{\max }$ were also lower in all diabetic groups indicating a development of myocardial dysfunction.

Effect of diabetes mellitus, NAC and L-NAME on susceptibility to ventricular arrhythmias

Myocardial ischemia resulted in a high ectopic activity in the control non-diabetic group, where VT represented the most severe type of arrhythmias that occurred in all hearts. In the diabetic hearts, we observed a marked attenuation in the occurrence of ventricular arrhythmias manifested by a lower total number of VPB 
VPB

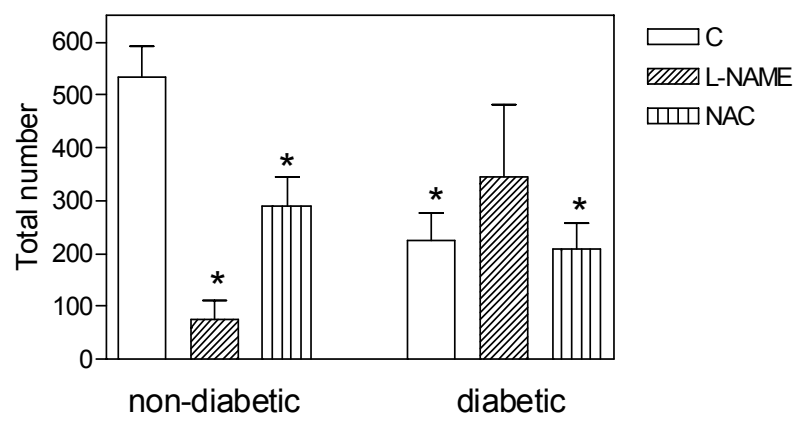

Fig. 1. Effect of NAC and L-NAME on ischemia-induced ventricular arrhythmias in the non-diabetic and diabetic rat heart. VPB - ventricular premature beats, $C$ - control non-treated groups, L-NAME - groups of hearts treated by L-NAME, NAC $\mathrm{N}$-acetylcysteine-treated groups. Values are means \pm S.E.M., $\mathrm{n}=6-11 .{ }^{*} \mathrm{P}<0.05$ vs. control non-diabetic hearts.

and shorter total duration of VT (Figs 1 and 2). In the non-diabetic hearts, pretreatment with NAC and L-NAME was antiarrhythmic and reduced the number of VPB (from $533 \pm 58$ in controls to $290 \pm 56$ and $74 \pm 36$, respectively), as well as decreased the total duration of VT (from $37.9 \pm 10.2 \mathrm{~s}$ in controls to $18.3 \pm 5.1$ and $13 \pm 5 \mathrm{~s}$, respectively). In contrast, both interventions exerted no additional antiarrhythmic effects in the diabetic hearts. Total number of VPB and duration of VT were not reduced in comparison with these parameters in the non-treated diabetic hearts (Figs 1 and 2; $\mathrm{P}>0.05$ ).

\section{Effect of diabetes mellitus on the levels of endogenous antioxidants}

Diabetic state was associated with significantly elevated levels of $\mathrm{CoQ}_{10}$ and $\mathrm{CoQ}_{9}$ (19.6 \pm 0.8 and 217.3 \pm 9.5 vs. $17.4 \pm 0.5$ and $185.0 \pm 5.0 \mathrm{nmol} / \mathrm{g}$, respectively, in the non-diabetic controls; $\mathrm{P}<0.05)$, as well as in $\alpha$-tocopherol $(38.6 \pm 0.7$ vs. $31.5 \pm 2.1 \mathrm{nmol} / \mathrm{g}$ the non-diabetic controls; $\mathrm{P}<0.01)$ in the heart ventricular tissue (Table 2).

\section{Discussion}

This study demonstrated that despite the development of myocardial dysfunction, early period of DM is associated with an enhanced resistance to ischemia-induced arrhythmias. Greater tolerance to ischemic injury observed in the diabetic heart can be considered as an alternative form of intrinsic cardioprotection analogous to that induced by short-term adaptive phenomenon known as ischemic preconditioning in the normal heart, in which numerous metabolic stimuli,
VT

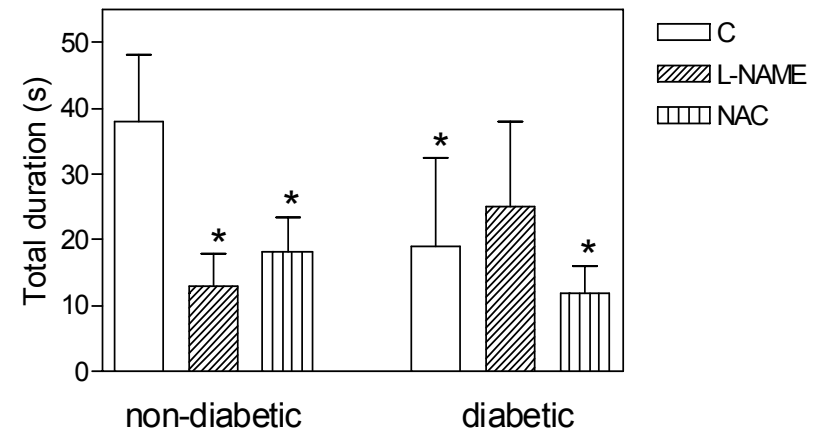

Fig. 2. Effect of NAC and L-NAME on total duration of ventricular tachycardia in the non-diabetic and diabetic rat hearts. VT ventricular tachycardia, other abbreviations as in Fig. 1. Values are means \pm S.E.M., $\mathrm{n}=6-11$. $^{*} \mathrm{P}<0.05$ vs. control non-diabetic hearts.

Table 2. Effect of acute diabetes mellitus on the tissue levels of endogenous antioxidants in the diabetic and non-diabetic rat hearts.

\begin{tabular}{lcc} 
Groups & $\begin{array}{c}\text { Non-diabetic } \\
(\mathbf{n}=\mathbf{1 1})\end{array}$ & $\begin{array}{c}\text { Diabetic } \\
(\mathbf{n}=7)\end{array}$ \\
\hline $\mathrm{Co} Q_{10}(\mathrm{nmol} / \mathrm{g})$ & $17.4 \pm 0.5$ & $19.6 \pm 0.8^{*}$ \\
$\mathrm{Co} Q_{9}(\mathrm{nmol} / \mathrm{g})$ & $185.0 \pm 5.0$ & $217.3 \pm 9.5^{*}$ \\
$\alpha$-tocopherol $(\mathrm{nmol} / \mathrm{g})$ & $31.5 \pm 2.1$ & $38.6 \pm 0.7^{* *}$ \\
\hline
\end{tabular}

Data are means \pm S.E.M. $\mathrm{CoQ}_{10}$ - coenzyme $\mathrm{Q}_{10} ; \mathrm{CoQ}_{9}-$ coenzyme $\mathrm{Q}_{9}$. * $\mathrm{P}<0.05$; ** $\mathrm{P}<0.01$ vs. non-diabetic control hearts.

in particular those related to oxidative stress and increased intracellular calcium signaling can trigger protection against ischemia/reperfusion (Meldrum et al. 1996). Increased contents of endogenous antioxidants, such as $\mathrm{CoQ}_{10}$ and in particular $\mathrm{CoQ}_{9}$, may be considered as a manifestation of the adaptive response in the rat diabetic myocardium (Kucharská et al. 2001) demonstrated also in the non-diabetic hearts exposed to ischemic preconditioning (Matejíková et al. 2007). Higher activities of antioxidant enzymes and concentration of antioxidants in the models of experimental diabetes have been also reported by other authors (Jain et al. 1995, Volkovová et al. 1997). In the study of Chen et al. (2006), higher resistance of the diabetic hearts to ischemia-reperfusion injury was also associated with an increased antioxidant capacity of the myocardium already in the acute phase of streptozotocininduced diabetes with severe hyperglycemia (blood glucose higher than $20 \mathrm{mmol} / \mathrm{l}$ ), or when the hearts were perfused with a high concentration of glucose. Induction 
of the adaptive mechanisms in the diabetic myocardium might be partially related to an enhanced production of NO (specifically by inducible NOS) and ROS (Singal et al. 2001, El-Omar et al. 2003, Cheng et al. 2005) that have been implicated as signaling molecules in protective mechanisms of both, short-term and long-lasting cardiac adaptation (Andelová et al. 2006, Pintérová et al. 2006). Based upon the results of this study we propose that these processes might modify a response of the diabetic heart to antioxidant treatment. The latter might result in a reduced effectiveness of NAC to further suppress arrhythmias in the diabetic myocardium. Similarly, pretreatment with L-NAME that was found cardioprotective in the normal non-adapted heart and reduced the extent of ischemiareperfusion injury (Andelová et al. 2005), in our study was antiarrhythmic only in the non-diabetic hearts. In the non-diabetic preconditioned myocardium, L-NAME suppressed increased ischemic tolerance (Andelová et al. 2005) and therefore, its antiarrhythmic effect might be attenuated under conditions of the diabetic state as well. The latter indicates that both, cardioprotection conferred by ischemic preconditioning in the healthy heart and increased resistance to ischemia in the diabetic myocardium might share similar molecular protective pathways. These results are supported by the study of Chen et al. (2006) who demonstrated that in the presence of L-NAME heart function was preserved, whereas reperfusion arrhythmias were increased in the diabetic heart, suggesting an involvement of $\mathrm{NO}$ in the mechanisms of protection in the diabetic myocardium. In conclusion, our results demonstrate that resistance to ischemia-induced ventricular arrhythmias and the levels of endogenous antioxidants are increased in the diabetic myocardium and that under these conditions, limitation of production of ROS and NO does not confer any additional antiarrhythmic protection.

\section{Conflict of Interest}

There is no conflict of interest.

\section{Acknowledgements}

This study was supported by grants VEGA SR 2/5110/25, 1/3442/06, 2/0173/08 and APVT 51-027404.

\section{References}

ANDELOVÁ E, BARTEKOVÁ M, PANCZA D, STYK J, RAVINGEROVÁ T: The role of NO in ischemia/reperfusion injury in isolated rat heart. Gen Physiol Biophys 24: 411-426, 2005.

ANDELOVÁ E, PINTÉROVÁ M, ŠIMONČÍKOVÁ P, BARANČÍK M, ONDREJČÁKOVÁ M, PECHÁŇOVÁ O, STYK J, RAVINGEROVÁ T: Dual role of NO in susceptibility to ischemia/reperfusion injury in the rat heart. Physiol Res 55: 1P, 2006.

BOLLI R: Cardioprotective function of inducible nitric oxide synthase and role of nitric oxide in myocardial ischemia and preconditioning: an overview of a decade of research. J Mol Cell Cardiol 33: 1897-1918, 2001.

CHEN H, SHEN WL, WANG XH, CHEN HZ, GU JZ, FU J, NI YF, GAO PJ, ZHU DL, HIGASHINO H: Paradoxically enhanced heart tolerance to ischaemia in type 1 diabetes and role of increased osmolarity. Clin Exp Pharmacol Physiol 33: 910-916, 2006.

CHENG X, XIA Z, LEO JM, PANG CC: The effect of N-acetylcysteine on cardiac contractility to dobutamine in rats with streptozotocin-induced diabetes. Eur J Pharmacol 519: 118-126, 2005.

EL-OMAR MM, LORD R, DRAPER NJ, SHAH AM: Role of nitric oxide in posthypoxic contractile dysfunction of diabetic cardiomyopathy. Eur J Heart Fail 5: 229-239, 2003.

FEUVRAY D, LOPASCHUK GD: Controversies on the sensitivity of the diabetic heart to ischemic injury: the sensitivity of the diabetic heart to ischemic injury is decreased. Cardiovas Res 34: 113-120, 1997.

FORRAT R, SEBBAG L, WIENSPERGER A, GUIDOLLET J, DELAYE J, DE LORGERIL M: Acute myocardial infarction in diabetic dogs with experimental diabetes. Cardiovasc Res 27: 1908-1912, 1993.

FERDINANDY P, SCHULZ R: Nitric oxide, superoxide, and peroxinitrite in myocardial ischemia-reperfusion injury and preconditioning. Br J Pharmacol 138: 532-543, 2003.

GALINANES M, FOWLER AG: Role of clinical pathologies in myocardial injury following ischaemia and reperfusion. Cardiovasc Res 61: 512-521, 2004.

HADOUR G, FERRERA R, SEBBAG L, FORRAT R, DELAYE J, DE LORGERIL M: Improved myocardial tolerance to ischemia in the diabetic rabbit. J Mol Cell Cardiol 30: 1869-1875, 1998. 
JAIN SK, LEVINE SN: Elevated lipid peroxidation and vitamin E-quinone levels in heart ventricles of streptozotocintreated diabetic rats. Free Radic Biol Med 18: 337-341, 1995.

KANNEL WB, MCGEE DL: Diabetes and cardiovascular risk factor. The Framingham Study. Circulation 59: 8-13, 1979.

KUCHARSKÁ J, GVOZDJAKOVÁ A, ŠTEFEK M, SOTNÍKOVÁ R, SUMBALOVÁ Z: Adaptive changes of antioxidant status in development of experimental diabetes. Bratisl Lek Listy 102: 515-519, 2001.

KUSAMA Y, HEARSE DJ, AVKIRAN M: Diabetes and susceptibility to reperfusion-induced ventricular arrhythmias. J Mol Cell Cardiol 24: 411-421, 1992.

LANG JK, GOHIL K, PACKER L: Simultaneous determination of tocopherols, ubuquinols, and ubiquinones in blood, plasma, tissue homogenates, and subcellular fractions. Anal Biochem 157: 106-116, 1986.

LECOUR S, MAUPOIL V, ZELLER M, LAUBRIET A, BRIOT T, ROCHETTE L: Levels of nitric oxide in the heart after experimental myocardial ischemia. J Cardiovasc Pharmacol 37: 55-63, 2001.

LIU Y, THORNTON JD, COHEN MV, DOWNEY JM, SCHAFFER SW: Streptozotocin-induced non-insulin dependent diabetes protects the heart from infarction. Circulation 88: 1273-1278, 1993.

MALMBERG K, RYDEN L: Myocardial infarction in patients with diabetes mellitus. Eur Heart J 9: 259-264, 1988.

MATEJÍKOVÁ J, KUCHARSKÁ J, PINTÉROVÁ M, RAVINGEROVÁ T: Involvement of mito $\mathrm{K}_{\text {ATP }}$ channels and reactive oxygen species in antiarrhythmic effect of ischemic and pharmacological preconditioning of the rat heart. Physiol Res 56: 22P, 2007.

MELDRUM DR, CLEVELAND JC JR, SHERIDAN BC, ROWLAND RT, BANERJEE A, HARKEN AH: Cardiac preconditioning with calcium: clinically accessible myocardial protection. J Thorac Cardiovasc Surg 112: 778786, 1996.

PAULSON DJ: The diabetic heart is more sensitive to ischemic injury. Cardiovasc Res 34: 104-112, 1997.

PIERCE GN, RAMJIAWAN B, DHALLA NS, FERRARI R: $\mathrm{Na}^{+}-\mathrm{H}^{+}$exchange in cardiac sarcolemmal vesicles isolated from diabetic rats. Am J Physiol 258: H255-H261, 1990.

PINTÉROVÁ M, PANCZA D, RAVINGEROVÁ T: The role of free radicals and mitochondrial $\mathrm{K}_{\mathrm{ATP}}$ channel modulations in the mechanisms of short-term cardioprotection in the rat heart. Physiol Res 55: 1P-2P, 2006.

SINGAL PK, BELLO-KLEIN A, FARAHMAND F, SANDHAWALIA V: Oxidative stress and functional deficit in diabetic cardiomyopathy. Adv Exp Med Biol 498: 213-220, 2001.

TOSAKI A, ENGELMAN DT, ENGELMAN RM, DAS DK: The evolution of diabetic response to ischemia/reperfusion and preconditioning in isolated working rat hearts. Cardiovasc Res 31: 526-536, 1996.

VEGH A, SZEKERES L, PARRATT JR: Preconditioning of the ischemic myocardium: involvement of the L-arginine nitric oxide pathway. Br J Pharmacol 107: 648-652, 1992.

VOLKOVOVÁ K, ZIEGELHÖFFER A, STARUCHOVÁ M, ONDREIČKA R: Relationship between some biochemical parameters in blood and myocardial tissue and the tolerance of the heart to calcium in different stages of experimental diabetes (in Slovak). Kardiologia 6: 152-157, 1997.

WALKER MJ, CURTIS MJ, HEARSE DJ, CAMPBELL RW, JANSE MJ, YELLON DM, COBB E SM, COKER SJ, HARNESS JB, HARRON DW, HIGGINS AJ, JULIAN DG, LAB MJ, MANNING AS, NORTHOVER BJ, PARRATT JR, RIEMERSMA RA, RIVA E, RUSSELL DC, SHERIDAN DJ, WINSLOW E, WOODWARD B: The Lambeth Conventions: guidelines for the study of arrhythmias in ischaemia infarction, and reperfusion. Cardiovasc Res 22: 447-455, 1988. 